\title{
Implementation of e-cigarette regulation through the EU Tobacco Products Directive (2016) in Wales, Scotland and England from the perspectives of stakeholders involved in policy introduction and enforcement
}

Rachel Brown' ${ }^{1}$,Jordan Van Godwin ${ }^{1}$, Nick Page ${ }^{1}$, Linda Bauld ${ }^{2,3}$, Jennifer McKell ${ }^{4,5}$, Britt Hallingberg ${ }^{6}$, Olivia Maynard ${ }^{7,8}$, Anna Blackwell ${ }^{7,8}$, Graham Moore ${ }^{1,3}$

\begin{abstract}
INTRODUCTION From May 2016, the European Union introduced the Tobacco Products Directive (TPD) regulations, which included restrictions to advertising and new safety and labeling standards for e-cigarette products. This represented the first supranational policy regulating e-cigarette sales and marketing. This study explores perceptions of TPD and its implementation in Wales, Scotland and England, from perspectives of stakeholders involved in tobacco and e-cigarette policy and implementation in each nation.
\end{abstract}

METHODS Semi-structured qualitative interviews were completed with 12 stakeholders from government and third sector organizations in the UK involved in tobacco control policy-making processes, and Trading Standards Officers from 13 UK local authorities. Data were analyzed thematically and a sub-sample double-coded.

RESULTS Stakeholders held varying views of e-cigarettes, recognizing potential benefits and harms of both the products and the new policy actions. Nevertheless, most perceived TPD to be a positive step in introducing regulation for e-cigarettes. Compliance was perceived as high across nations, although stakeholders highlighted product adaptations to circumvent restrictions, and absence of controls on non-nicotine products. Budgetary and staffing limitations also meant that capacity to communicate new measures, and enforce change, was limited. This led to a gap occupied by industry representatives, who played a substantial role in preparing retailers for adoption of new measures.

CONCLUSIONS TPD policy roll-out was largely perceived positively and as having been effectively implemented. However, contribution of industry to communication of new measures and absence of resourcing for effective communication perhaps introduced widespread innovations within regulations. While largely viewed positively, some refinements to device regulations were proposed.

\section{AFFILIATION}

1 Centre for Development, Evaluation, Complexity and Implementation in Public Health Improvement, (DECIPHer), School of Social Sciences, Cardiff University, Cardiff, United Kingdom

2 Usher Institute of Population Health Sciences and Informatics, University of Edinburgh, Edinburgh, United Kingdom 3 SPECTRUM Consortium, United Kingdom 4 Institute for Social Marketing and Health, University of Stirling, Stirling, United Kingdom

5 UK Centre for Tobacco and Alcohol Studies, Stirling, United Kingdom 6 Cardiff School of Sport and Health Sciences, Cardiff Metropolitan University, Cardiff, United Kingdom

7 MRC Integrative Epidemiology Unit, University of Bristol, Bristol, United Kingdom

8 School of Psychological Science, University of Bristol, Bristol, United Kingdom

9 The Shaping Public hEalth poliCies To Reduce IneqUalities and harm (SPECTRUM) Spectrum Consortium, University of Edinburgh, Edinburgh, United Kingdom

\section{CORRESPONDENCE TO}

Rachel Brown. Centre for Development, Evaluation, Complexity and Implementation in Public Health Improvement, (DECIPHer),

School of Social Sciences, Cardiff

University, Cardiff, CF10 3AT, United Kingdom. E-mail: brownr14@cardiff.ac.uk ORCID ID: https://orcid.org/0000-00024475-1733

KEYWORDS

UK, tobacco, e-cigarettes, policy, qualitative

Received: 18 January 2021

Revised: 15 March 2021

Accepted: 15 March 2021 


\section{INTRODUCTION}

In the UK, substantial declines in tobacco use in recent decades have resulted in historically low levels of regular smoking among adults and young people ${ }^{1}$. These declines are widely acknowledged to be attributed to implementation of policy measures at multiple system levels ${ }^{2}$, from individually-targeted actions such as education campaigns and smoking cessation programs, to national policies such as price and taxation increases and restrictions on advertising. In recent years - and alongside this continued decline - use of e-cigarettes has increased rapidly since their emergence in UK markets, with an estimated increase from 0.70 million adult users in 2012 to about 3.6 million in $2019^{3}$. While evidence suggests that e-cigarettes can effectively contribute to smoking cessation $^{4}$, evidence of direct harm remains unclear, necessitating efforts to limit use, particularly amongst non-smoking adults and young people.

Within the UK, responsibility for tobacco and e-cigarette policy falls to both UK government and the devolved administrations in Wales, Scotland and Northern Ireland. This means that some aspects of regulation are variably implemented across the nations (e.g. increase in age of sale from 16 to 18 years, ban on point-of-sale displays), while others are introduced more uniformly (e.g. implementation of plain packaging). However, the extent of local variations is minimized in light of the WHO Framework Convention on Tobacco Control $(\text { FCTC })^{5}$ - a global convention which calls on nations to adopt measures such as: creation of smoke-free public spaces; bans on tobacco advertising and sponsorship; and inclusion of health warnings on packaging.

For e-cigarettes, there is no equivalent global policy to FCTC, providing greater opportunity for divergence in international approaches and legislation. In May 2016, the European Union (EU) revised Tobacco Products Directive (TPD) was introduced across EU member states, with a 12 -month implementation period for retailers to transition to compliant products. Widespread age of sale restrictions on e-cigarettes were already in place in many European countries prior to TPD ${ }^{6}$, with restrictions in sales to those aged $<18$ years introduced in England and Wales from October $2015^{7}$, although later in Scotland with introduction in $2017^{8}$. However, the revised TPD constitutes the first supranational, shared guidance on e-cigarettes with the potential to standardize regulation across multiple countries. TPD introduced a range of new measures governing sales and marketing for tobacco and e-cigarette products, including bans on crossborder marketing (in force immediately); mandatory warnings on e-cigarette products containing nicotine; and restrictions on available sizes for both e-liquids and devices (phased over 12 months) ${ }^{9}$.

The UK's departure from the EU introduces capacity to diverge from the TPD and the UK government has committed to a policy review in $2021^{10}$. It is therefore important to understand the implementation of TPD from the perspectives of key stakeholders to future inform interpretation of effectiveness. This study explores implementation of the e-cigarette measures of the TPD policy in Wales, Scotland and England from the perspective of tobacco control policy stakeholders and Trading Standards Officers (TSOs). It considers barriers and facilitators to implementation of key policy components, local and national variations, and the wider tobacco control context.

\section{METHODS}

This study presents findings from qualitative interviews carried out within an on-going mixedmethods evaluation of the impact of the EU TPD on youth e-cigarette use in the $\mathrm{UK}^{11}$. Interviews occurred approximately a year after the end of the transitional period for TPD (between June and November 2018). Semi-structured interviews were conducted with 12 stakeholders working in government and third sector organizations involved in tobacco control policymaking processes in Wales, England and Scotland (referred to below as 'policy stakeholders'). The sample is described in Table 1 but with removal of specific job roles and organizational details. Participants were identified through pre-established networks of the research team, who have significant experience in the field of tobacco control research, and through searching key websites of organizations identified as having the specialist knowledge required. All of those approached for interview agreed to participate. Semi-structured interviews were also conducted with TSOs in England, Scotland and Wales. Ten areas in each of Scotland and Wales were 
purposively sampled for approach, to include north, south and mid regions, as well as a range of both urban and rural locations. In England, ten areas within South West England were sampled, including both urban and rural centers. Of these, 13 different local authorities agreed to participate.

Topic guides were developed to address the research questions of the wider study. Interviews focused on: policy implementation and compliance; local contextual factors and variations in e-cigarette policy; and theorized mechanisms of the TPD legislation in relation to e-cigarettes. Topic guides were not prescriptive and allowed flexibility in response to the roles of interviewees, for example, with less emphasis on policy development and more on enforcement activity when speaking with TSOs. While sampled due to their professional positions, interviews focused on participants' views of e-cigarettes and their regulation, rather than necessarily representing the positions of their organizations. All interviewees received an information sheet and consent form in advance

\section{Table 1. Policy stakeholder group}

\begin{tabular}{|c|c|c|}
\hline Code & Country & Role \\
\hline E1 & England & $\begin{array}{l}\text { Tobacco control advocate within the } \\
\text { voluntary sector }\end{array}$ \\
\hline E2 & England & $\begin{array}{l}\text { Tobacco control advocate within the } \\
\text { voluntary sector }\end{array}$ \\
\hline E3 & England & $\begin{array}{l}\text { Contributor to tobacco control within } \\
\text { government }\end{array}$ \\
\hline E4 & England & $\begin{array}{l}\text { Contributor to tobacco control within } \\
\text { government }\end{array}$ \\
\hline E5 & England & $\begin{array}{l}\text { Contributor to tobacco control within } \\
\text { public sector organization }\end{array}$ \\
\hline S1 & Scotland & $\begin{array}{l}\text { Contributor to tobacco control role within } \\
\text { government }\end{array}$ \\
\hline S2 & Scotland & $\begin{array}{l}\text { Contributor to tobacco control within } \\
\text { public sector organization }\end{array}$ \\
\hline S3 & Scotland & $\begin{array}{l}\text { Tobacco control advocate within the } \\
\text { voluntary sector }\end{array}$ \\
\hline W1 & Wales & $\begin{array}{l}\text { Contributor to tobacco control within } \\
\text { public sector organization }\end{array}$ \\
\hline W2 & Wales & $\begin{array}{l}\text { Tobacco control advocate within the } \\
\text { voluntary sector }\end{array}$ \\
\hline W3 & Wales & $\begin{array}{l}\text { Contributor to tobacco control role within } \\
\text { government }\end{array}$ \\
\hline W4 & Wales & $\begin{array}{l}\text { Tobacco control advocate within the } \\
\text { voluntary sector }\end{array}$ \\
\hline
\end{tabular}

of interviews and were advised of how their data would be used, as well as their right to withdraw and to review interview transcripts. Research was approved by Cardiff University School of Social Sciences Research Ethics Committee. Interviews were conducted either face-to-face or by telephone and lasted between 30-60 minutes. Interviews were led by different members of the research team in the different nations. All interviews were recorded and transcribed verbatim.

\section{Statistical analysis}

Analysis drew on Critical Realism, identifying social practices, social systems and participant interpretations of those systems ${ }^{12}$, to understand interactions between the context, policy mechanisms and observed outcomes during the implementation process ${ }^{13}$.

Thematic analysis ${ }^{14}$ was first undertaken on the policy stakeholder interviews by the lead author, with a coding frame developed from repeat reading of transcripts to identify emerging themes and also guided by the themes used with the interview topic guide. The initial coding frame was applied to a subsample of transcripts from the policy stakeholder group. The coding frame was then refined through discussion within the research team, drawing on initial insights from this first phase, and the finalized framework was then applied to all transcripts, with full thematic analysis completed by the lead author and second coding of a sample of transcripts completed by another research team member. The same process was then followed for TSO interviews, before a third phase of comparative analysis was undertaken across the two datasets to identify new themes and areas of divergence and convergence.

Policy stakeholder participants are identified by country code (W=Wales; $\mathrm{S}=$ Scotland; $\mathrm{E}=$ England), followed by a number corresponding to the order of interview. TSO interviewees are identified by TS and number order, followed by country code e.g. TS1(W). Quotes are used to illustrate key ideas and insights, not to imply uniformity of views, and variations in opinion are included where relevant.

\section{RESULTS}

\section{Stakeholders' views on e-cigarettes}

Interviews commenced with a general discussion of 
the emergence of e-cigarettes onto the UK market and the ways in which this constituted a positive or negative outcome for public health. There was broad agreement on the overall aim of public health policy in relation to e-cigarettes as reducing access to - and use by - non-smokers, while exploring potential benefits to smokers, encapsulated as 'maximizing the opportunities while minimizing the risks' (E5).

Responses on how to actually achieve this reflected the complexities of assessing harm in relation to e-cigarettes rather than indicating clear positions of support or disapproval. Many acknowledged a positive role in tobacco reduction while also expressing caution over, as yet, unknown harms, and views were divided between those who supported more active promotion of e-cigarettes as cessation aids and those who favored a 'better safe than sorry' approach based on the relative newness of the product. This difference was observed at national level in relation to smoking cessation, with Wales considered by some to be displaying more caution in incorporating e-cigarettes into smoking cessation services than public health bodies in Scotland and England:

'So I think it's a done deal in England I don't think anybody would seriously doubt it and in Scotland as well. In Wales there's a debate.' (E5)

This debate was evident in responses from participants in Wales, with observable differences in outlook between public and third sector respondents and notably more caution among those in the public sector, as illustrated by W1:

'I would feel stronger, personally in favor of no e-cigarettes, on grounds that they would look at normalizing smoking. I would rather remove e-cigarettes than use them as a Stop Smoking medicine.' (W1)

'Our view on that is one that if people are happy to use e-cigarettes as a form of smoking cessation, then we would encourage it.' (W4)

\section{Perceptions of key elements of TPD's e-cigarette regulations}

Both policy and TSO respondents were asked for their views on the key measures being introduced within TPD that related to e-cigarettes. Discussions centered on the main policy elements and included the introduction of warning labels, restrictions on liquids and device sizes and changes to packaging. Overall, there was broad agreement that TPD was a welcome step in regulating the e-cigarette market, with strong agreement on the benefits of a product and ingredient regulatory system as a means of increasing public safety and promoting consistent practice, and consensus that marketing restrictions were sensible. Many supported the introduction of a warning label on packaging:

'I think it's really good especially in relation to all the warning notices that you need on there ... I think it's really good, very comprehensive in relation to the labelling requirements on there.' (TS3, W)

However, several participants perceived the actual content of the message introduced through TPD ('This product contains nicotine which is a highly addictive substance') to be problematic, and potentially conflicting with previous approaches to nicotine provision:

'So I find this slightly confusing, I've heard people suddenly talking about nicotine in a way which I don't remember anyone talking about nicotine before ... so we've had NRT for what, I don't know, about twenty years? I don't think there is a warning on NRT saying this contains nicotine which is really highly addictive ... so why don't we have warnings on NRT?' (S1)

Other limitations introduced through TPD included a cap on the amount of nicotine contained within e-liquids and restrictions on tank sizes of e-cigarettes which limit the volume of e-liquid held. Some questioned the evidentiary basis and the likely effectiveness of these specific elements of the legislation, highlighting a potential risk of deterring those who have switched from tobacco use to e-cigarettes:

'The tank size is not based on any evidence and it is annoying for people to have to continually fill up ... and it's expensive way of doing things. There will probably be people who will have gone back to smoking because they can't take the cuffuffle of it.' (S2)

TSOs discussed market and consumer responses to the policy, including loopholes to circumvent restrictions such as the increasingly common practice of 'short-fills', where retailers sell larger refill bottles partially filled with non-nicotine e-liquids, with space for the consumer to add their own liquid 
nicotine. This enables retailers to remain compliant with TPD regulations while allowing consumers to create higher strength liquids.

'The bigger bottles, because they're limited in legislation to size, to $10 \mathrm{mil}$ at the moment, the bigger bottles (of non-nicotine liquids) have a gap in the top, the idea being that you can add nicotine shots into it and create the strength that you require.' (TS2, E)

The consumers' control over the addition of nicotine was considered problematic for Trading Standards:

'Yes it does make it difficult. We can't enforce that because you've got two products which are compliant, they are being sold compliant and then it's the individual person who is buying them that makes it non-compliant. There is no offence there, because the consumer is then tampering with it. So, they're taking that risk on board themselves.' (TS4, S)

Further unintended outcomes included modification of devices to increase the capacity of e-liquid tanks to allow the consumer to refill less often:

'The way that a lot of the manufacturers reacted was to tweak and modify their products, so I'll give you a specific example. So, with tanks, the tanks are limited but what happened almost immediately is that the tanks would then be supplied with a TPD compliant size tank but then with another piece of glass that would mean that you could extend the tank.' (TS3, E)

\section{The process of implementing TPD}

The period before and after the initial implementation of the TPD policy was discussed. Retailer awareness of the new requirements was described as 'a little on the back foot' (TS1, S) when compared with tobacco but improving over the course of the transition period. The range of retailers selling e-cigarette products, coupled with limited resources for communication of the new legislation, meant that what resources were available to those communicating and enforcing the policy were concentrated on those involved in e-cigarette production and distribution rather than trying to reach all retailers individually:

'... so our efforts in communicating this has been through retailers federations and through local authorities.' (S2)

While a perceived benefit of TPD was that it may provide consistent practice through clarity of message across both counties and UK nations, absence of resourcing for public health bodies and TSOs to communicate this led to a suggested risk of loss of control over message content when gaps were filled by e-cigarette vape trade representatives:

'I think their communication about, you know on the vaping side at least was not very good for the public. I don't think people really understood the changes that were happening, I think a lot of vapers were obviously affected by the changes, that wasn't very well communicated by the government. It was more the industry themselves were putting out those messages.' (E1)

Some TSOs suggested that industry involvement was a result of a lack of clarity in messaging to date from local and national government:

'But e-cigarettes was interesting, because most people didn't really understand it, because it was a new, and it wasn't regulated, and then it was regulated ... So there was information, and I think the picture that was being given out, the message wasn't probably necessarily consistent. I think the people even in regulatory services, and potentially local government, were quite unsure really as to how to deal with these.' (TS2, W)

For TSOs, all interviewees cited lack of resources and staffing cuts over recent years as a barrier to being able to effectively communicate with as many retailers as they desired, including a ' $50 \%$ decrease in trading standards officers across the country and over the last few years' (TS5, S). Many discussed priority areas that had become more central to their roles in recent years, including illicit tobacco and alcohol, modern slavery and criminal gang activity. Both Wales and England reported bespoke enforcement activity on e-cigarettes, with shortterm funding being made available for selected local authorities to carry out retailer compliance checks in the period leading up to TPD roll-out. TSOs in all nations reported increased visits to retail premises during the 12-month implementation period, but only those in Scotland reported ring-fenced funding for TPD-related activities, including visits to retailers and test-purchasing to encourage retailers to ask for age verification for e-cigarette purchases. 
In all nations it was stated that funding had not been sufficient to reach most retailers or to sustain compliance activities.

Following the conclusion of the implementation period, when e-cigarette monitoring had become part of standard practice, activity was described as intelligence-led, meaning officers would visit premises only if a complaint had been received. However, this was described as very unusual:

'E-cigarettes, it's not something really that we've ever had much in the way of complaint about ... the level of complaints to most local authorities are very low. Schools don't tend to report it, and parents don't tend to report it very often.' (TS2, W)

Despite these limitations, overall retailer compliance was viewed positively in most areas. For specialist e-cigarette retailers, the role of trade bodies was acknowledged as important in ensuring that their members were aware of the legislation in advance. Further, manufacturing changes to produce newly compliant stock meant that many retailers were compliant by default, with old stock simply no longer available.

Where issues of non-compliance remained, these were largely perceived as being among nonspecialist stores and those where e-cigarettes constituted a small part of the business:

'It is really these corner shop style of shop, your little local that has a load of e-cigarettes sitting on the shelf for the last couple of years. Nobody is buying it but they just keep it on the shelf, but actually it's non-compliant.' (TS1, S)

One TSO noted that the rapid growth of the e-cigarette retail market among stores with little experience of age-restricted products meant that staff awareness of regulation, and the need to carry our age-verification checks, was lower than in stores which traditionally sold tobacco or alcohol:

'You can get it in a shoe shop or you can get it in a boutique or a chemist. So they never had to bother about age restricted products before. A watch repairer, mobile phone shops. People who have never had to deal with age restricted products are selling NVPs (nicotine vaping products) and it's like, "I don't ask anybody anything".' (TS2, S)

These stores were also more likely to be operating outside of the trade associations and bodies that had contributed to communication of TPD.

\section{Considering future policy continuity and changes}

Most respondents felt that despite the UK leaving the EU, policy trajectories for tobacco would largely remain unchanged, with most respondents approving the general direction of UK tobacco control and its progressive movement toward increasingly strict regulation:

'... as I said before we've gone further than the EU on most things so our advertising, tobacco advertising directive we go further than that in what we prohibit in terms of advertising, promotion and sponsorship. So we don't just prohibit cross border advertising, promotional sponsorship we prohibit all advertising promotions and sponsorship. So there's no reason why leaving the EU would change because that's all translated into UK regulation.' (E2)

It was suggested, however, that in many ways, e-cigarettes are unique products presenting somewhat different regulatory challenges and that review may already be needed in response to new and emerging product adaptations:

'With e-cigarettes it is so fast paced that I don't think regulations are fit for their purpose, purely because they are outdated and these loopholes seem to happen, that people didn't expect to happen, and to regulate that is, I think it will be very, very difficult.' (TS1, E)

'I think TPD made an attempt to kind of catch a novel product, but we didn't necessarily foresee the ... some of the kind of complexities raised by products like Juul and other things, where the regulatory ... legislative framework from stuff like that, is slightly behind the innovations that are in the market.' (E3)

Potential refinements to current e-cigarette policy included reviewing restrictions on tank sizes, increased regulation of non-nicotine e-liquids, and introducing standardized packaging for e-liquids:

'One thing I would say is it would be good to see standardized packaging coming in for e-cigarettes, the same way as they did with tobacco. There is talk that it will eventually.' (TS3, S)

\section{DISCUSSION}

This research explores key stakeholder perceptions of the implementation of the EU Tobacco Products Directive in relation to e-cigarettes across three 
UK nations, where responsibility for tobacco and e-cigarette legislation is a mix of national and devolved-government responsibility.

Respondents identified similar concerns over implementation processes including: the impact of budgetary constraints on enforcement; complexities in the types of retailers involved in sales of e-cigarettes; and concerns over the role of industry in communication of new policy measures. While compliance with the product labelling requirements of TPD among retailers is relatively high $^{15}$, this study suggests that this was partially due to the involvement of outside parties, including trade bodies and manufacturers, who were key in communicating with retailers where public bodies lacked the capacity to do so. While there was limited discussion of the tobacco industry in these interviews, the growth of the tobacco industry as owners of e-cigarettes and related products ${ }^{16}$ and the potential for commercial interests to be drivers of messaging may be an area of concern.

Evidence indicates that enforcement activity at local government level is key to ensuring retailer compliance with sales policies for tobacco ${ }^{17}$, suggesting that the absence of similar enforcement practices for e-cigarette policy may lead to less uniform adoption. Further, the financial investment and commitments to strong governance that have underpinned effective implementation of the FCTC $^{18}$ have not yet been replicated for e-cigarettes, risking more inconsistent and sporadic implementation of the TPD as the nearest equivalent supranational policy and making evaluation of the policy more challenging.

Understanding the implementation of the TPD is helpful in providing context for interpreting effects and planning for future tobacco control activities. In terms of the policy aim of minimizing youth use of e-cigarettes, evidence suggests that the growth in youth use observed in the UK since 2013 has not continued post-TPD ${ }^{19}$. However, it is as yet unclear if this is associated with the policy or with changing social trends in youth behavior that may have happened anyway ${ }^{20}$ and this absence of clarity is important in considering potential revisions to the TPD in the future. In light of UK capacity to review the TPD following the UK exit from the EU, several respondents suggested that those elements considered less effective may be amended in the future. The content of the mandatory warning message on packaging was highlighted as one such area, with suggestions that this should be reviewed alongside the aims of minimizing any risks associated with e-cigarette use, particularly by young people, while maximizing their potential role in smoking cessation ${ }^{21}$. It can be argued that, while health risks of e-cigarettes cannot be discounted ${ }^{22}$, greater health gains can be made by increasing the numbers of smokers who switch to exclusive use of the devices ${ }^{23}$. Evidence suggests that while the current warning message, mandated through the TPD, may be effective in increasing perceptions of harm among non-smokers ${ }^{24}$, it may also discourage smokers from switching to e-cigarettes ${ }^{25}$. The potential loss of public health benefits may prompt consideration of message content in the forthcoming UK review.

Within the UK, while e-cigarette policy between the nations is relatively uniform, the devolved structure means that supranational regulations such as TPD are introduced into contexts with some variations in tobacco and e-cigarette control. The level of similarity in tobacco control policy adoption seen across the nations, to date, may reflect the strong evidence-base for measures such as the ban on smoking in indoor spaces ${ }^{26}$, however devolution has presented opportunities for different approaches and innovations ${ }^{27}$. Examples of current divergence include the Register of Tobacco and Nicotine Vapor Product Retailers in operation in Scotland, which requires anyone selling such products to register with the Scottish Government, a system not currently in operation elsewhere. The devolved nature of some aspects of tobacco control within the UK nations means that it is theoretically possible that the individual nations will take different approaches to tobacco and e-cigarette policy in the future. It is possible that a greater degree of divergence may have been observed if not for delays to domestic policy agendas resulting from an increased focus on planning for the UK exit from the $\mathrm{EU}^{28}$. For example, the proposed Health (Tobacco, Nicotine etc. and Care) (Scotland) Bill (2015) introduced by the Scottish Government included the capacity to restrict: a) a nicotine vapor product adverts, and b) nicotine vapor product brand sharing; but which, 
as yet, has not been implemented. In late 2019 , this was re-visited by the Scottish Government, which began work on a consultation to consider restrictions in domestic advertising of e-cigarette products in 2020 , however, at the time of writing, this had not yet taken place due to disruption caused by COVID-19, and next steps remain unclear. In England, the direction of tobacco and e-cigarette policy has, in part, been driven by Public Health England ${ }^{29,30}$, including support for promotion of e-cigarettes within cessation services. However, recent changes to the delivery of public health in England, including the dissolution of Public Health England and its replacement by a new body with no stated remit for tobacco and e-cigarette control policy, mean that potential actions in England - and responsibility to review elements of the TPD - in the future are currently unclear.

In Wales, as recently as 2016, and shortly before the introduction of the TPD, the Welsh Government proposed a ban on e-cigarette use in public places. The measure, which was narrowly defeated, suggested a more aggressive approach to regulation, in line with participant views in this research. However, the Welsh Government 'Smoke-free Premises and Vehicles (Wales) Regulations 2020', in effect from March 2021, includes extensions to settings and spaces required to be smoke-free but applies only to tobacco, with no inclusion of e-cigarettes. This suggests a potential change in approach from the previous failed legislation and an approach more aligned with both Scotland and England. While other UK nations may also extend legislation on smoke-free settings in the future - as has happened historically - it is, as yet, unclear what approaches will be taken to e-cigarettes, and this should be monitored.

While most participants felt that the UK nations featured would continue to follow largely similar paths on future legislation, the devolved nature of legislative power within the UK suggests that this should be observed for further research in the future, as well as any areas where the UK may choose to diverge from EU-wide legislation following the exit from the EU. Further research should also consider the position in Northern Ireland and any changes to policy and practice that differ from the other UK nations.

\section{CONCLUSIONS}

In this research, most stakeholders perceived the regulation of e-cigarettes within the TPD positively. Any future review of these measures should include consideration of new product innovations designed to circumvent controls, as well as recent evidence on the effectiveness of product warning messages. The UK exit from the EU creates potential for divergence from the TPD in the future, along with possibilities of different approaches within the UK nations, however the situation is currently unclear in light of Brexit and COVID-19 related delays. Any such future diversion should be monitored for impact. While high levels of retailer compliance with the legislation suggests effective implementation, this study illustrates that this may have been due, not only to policy and enforcement activity, but to contributions from the industry groups to communication of the new measures. Policy adaptations should include increased communication planning to ensure that those within the retail market can be effectively reached with clear and consistent messaging driven by a public health agenda rather than a commercial one.

\section{REFERENCES}

1. Office for National Statistics. Adult smoking habits in the UK 2018: Cigarette smoking habits among adults in the UK, including the proportion of people who smoke, demographic breakdowns, changes over time, and use of e-cigarettes. Office for National Statistics; 2019. Published July 2, 2019. Accessed July, 2020. https:// www.ons.gov.uk/peoplepopulationandcommunity/ healthandsocialcare/healthandlifeexpectancies/bulletins/ adultsmokinghabitsingreatbritain/2018/pdf

2. Chung-Hall J, Craig L, Gravely S, Sansone N, Fong GT. Impact of the WHO FCTC over the first decade: a global evidence review prepared for the Impact Assessment Expert Group. Tob Control. 2019;28(Suppl 2):s119-s128. doi:10.1136/tobaccocontrol-2018-054389

3. Action on Smoking and Health. Use of e-cigarettes (vaporisers) among adults in Great Britain. Action on Smoking and Health; 2019. Accessed August, 2020. https://web.archive.org/web/20210303021226/https:// ash.org.uk/wp-content/uploads/2019/09/Use-of-ecigarettes-among-adults-2019.pdf

4. Hartmann-Boyce J, McRobbie H, Lindson $\mathrm{N}$, et al. Electronic cigarettes for smoking cessation. Cochrane Database Syst Rev. 2020;10:CD010216. doi:10.1002/14651858.CD010216.pub4

5. World Health Organization. WHO Framework Convention on Tobacco Control. World Health Organization; 
2003. Published 2003. Updated 2005. Accessed May, 2020. https://apps.who.int/iris/bitstream/ handle/10665/42811/9241591013.pdf

6. Global Tobacco Control. Country laws regulating e-cigarettes: Minimum age. Accessed September, 2020. https://globaltobaccocontrol.org/e-cigarette/minimumage.

7. Department of Health and Social Care. Rules about tobacco, e-cigarettes and smoking: 1 October 2015. Published July 9, 2015. Accessed June, 2020. https:// www.gov.uk/government/publications/new-rules-abouttobacco-e-cigarettes-and-smoking-1-october-2015/ new-rules-about-tobacco-e-cigarettes-and-smoking-1october-2015

8. Scottish Government. E-cigarette restrictions. Published April 1, 2017. Accessed December, 2020. https://www. gov.scot/news/e-cigarette-restrictions/

9. European Union. Directive 2014/40/EU of the European Parliament and of the Council of 3 April 2014 on the approximation of the laws, regulations and administrative provisions of the Member States concerning the manufacture, presentation and sale of tobacco and related products and repealing Directive 2001/37/EC. Published April 29, 2014. Accessed December, 2019. https:// ec.europa.eu/health//sites/health/files/tobacco/docs/ dir_201440_en.pdf

10. Department of Health and Social Care. Tobacco Control Plan Delivery Plan 2017 - 2022. Department of Health and Social Care; 2016. Accessed July, 2020. https:// assets.publishing.service.gov.uk/government/uploads/ system/uploads/attachment_data/file/714365/tobaccocontrol-delivery-plan-2017-to-2022.pdf

11. National Institute for Health Research. Impacts of e-cigarette regulation via the EU Tobacco Products Directive on young people's use of e-cigarettes : a natural experiment. Published February 4, 2019. Accessed July, 2020. https://www.journalslibrary.nihr.ac.uk/ programmes/phr/165701\#/

12. Bhaskar R. A Realist Theory Of Science. Verso; 1975.

13. Pawson R, Tilley N. Realistic Evaluation. Sage; 1997.

14. Braun V, Clarke V. Using thematic analysis in psychology. Qual Res Psychol. 2006;3(2):77-101. doi:10.1191/1478088706qp063oa.

15. MacGregor J. Rapid Review of Nicotine Inhaling Product Compliance with the Tobacco Product and Related Products Regulations 2017: Carried out by Trading Standards Services in England. MacGregor Consulting Limited for the Chartered Trading Standards Institute; 2018. Published May, 2018. Accessed June, 2020. https://www.tradingstandards.uk/media/documents/ news--policy/tobacco-control/rr1-phase-3-final-reportfor-dhsc.pdf

16. Maziak W. E-cigarettes: harm reduction or rehabilitation of the tobacco industry? Int J Public Health. 2020;65(2):159-161. doi:10.1007/s00038-019-01316-y
17. Jacobson PD, Wasserman J. The implementation and enforcement of tobacco control laws: policy implications for activists and the industry. J Health Polit Policy Law. 1999;24(3):567-598. doi:10.1215/03616878-24-3-567

18. Jarman H. Normalizing Tobacco? The Politics of Trade, Investment, and Tobacco Control. Milbank Q. 2019;97(2):449-479. doi:10.1111/1468-0009.12393

19. Moore G, Brown R, Hallingberg B, et al. Young people's use of e-cigarettes in Wales, England and Scotland before and after introduction of EU Tobacco Products Directive regulations: a mixed-method natural experimental evaluation. Int J Drug Policy. 2020;85:102795. doi:10.1016/j.drugpo.2020.102795

20. Brown R, Bauld L, de Lacy E, et al. A qualitative study of e-cigarette emergence and the potential for tobacco renormalisation of smoking in UK youth. Int J Drug Policy. 2020;75:102598. doi:10.1016/j.drugpo.2019.11.006

21. Hajek P, Phillips-Waller A, Przulj D, et al. A Randomized Trial of E-Cigarettes versus Nicotine-Replacement Therapy. N Engl J Med. 2019;380(7):629-637. doi:10.1056/NEJMoa1808779

22. Staudt MR, Salit J, Kaner RJ, Hollman C, Crystal RG. Altered lung biology of healthy never smokers following acute inhalation of E-cigarettes. Respir Res. 2018;19(1):78. doi:10.1186/s12931-018-0778-z

23. Warner KE, Mendez D. E-cigarettes: Comparing the Possible Risks of Increasing Smoking Initiation with the Potential Benefits of Increasing Smoking Cessation. Nicotine Tob Res. 2019;21(1):41-47. doi:10.1093/ntr/nty062

24. Kimber C, Frings D, Cox S, Albery IP, Dawkins L. Communicating the relative health risks of E-cigarettes: An online experimental study exploring the effects of a comparative health message versus the EU nicotine addiction warnings on smokers' and non-smokers' risk perceptions and behavioural intentions. Addict Behav. 2020;101:106177. doi:10.1016/j.addbeh.2019.106177

25. Cox S, Frings D, Ahmed R, Dawkins L. Messages matter: The Tobacco Products Directive nicotine addiction health warning versus an alternative relative risk message on smokers' willingness to use and purchase an electronic cigarette. Addict Behav Rep. 2018;8:136-139. doi:10.1016/j.abrep.2018.09.006

26. British Medical Association. Towards Smoke-free Public Places. British Medical Association; 2002. Accessed July, 2020. https://www.researchgate.net/ publication/281283733_Towards_smoke-free_public_ places_BMA_November_2002

27. Katikireddi VS, Smith KE, Stuckler D, McKee M. Devolution of power, revolution in public health? J Public Health. 2016;39(2):1-7. doi:10.1093/pubmed/fdw031

28. Andrews E. Domestic policy delays are a Brexit issue. Institute for Government. Published December, 2018. Accessed December, 2020. https://www. instituteforgovernment.org.uk/blog/domestic-policydelays-are-brexit-issue 
29. McNeill A, Brose LS, Calder R, Hitchman SC, Hajek P, McRobbie H. E-cigarettes: an evidence update: A report commissioned by Public Health England. Published August, 2015. Accessed December, 2020. https://assets. publishing.service.gov.uk/government/uploads/system/ uploads/attachment_data/file/733022/Ecigarettes_an_ evidence_update_A_report_commissioned_by_Public_ Health_England_FINAL.pdf

30. Public Health England. Evidence review of e-cigarettes and heated tobacco products 2018: A report commissioned by Public Health England, 2018: executive summary. Published February, 2018. Updated March 2, 2018. Accessed December, 2020. https://www.gov. uk/government/publications/e-cigarettes-and-heatedtobacco-products-evidence-review/evidence-review-of-ecigarettes-and-heated-tobacco-products-2018-executivesummary

\section{CONFLICTS OF INTEREST}

The authors have each completed and submitted an ICMJE form for disclosure of potential conflicts of interest. The authors declare that they have no competing interests, financial or otherwise, related to the current work. L. McKell, B. Hallingberg, J. Van Godwin, G. Moore, L. Bauld, O. Maynard and R. Brown report funds from NIHR Public Health Research. G. Moore also reports funds from UKCRC Consortium, Welsh Government via Health and Care Research Wales and Cardiff University, during the conduct of the study and grants from Cancer Research UK, NICE, NIHR, CRUK outside the submitted work. L. Bauld also reports grants from Medical Research Council, NIHR Public Health Research, Cancer Research UK and from UK Research Innovation, outside the submitted work. R. Brown also reports funding from Cardiff University during the conduct of the study, and grants from Cancer Research UK, outside the submitted work.

\section{FUNDING}

This work was supported by the National Institute for Health Research (NIHR) in England under its Public Health Research Board (Grant number $16 / 57 / 01)$. The views expressed in this manuscript are those of the authors and do not necessarily reflect those of the National Health Service (NHS), the NIHR or the Department of Health for England.

The work was undertaken with the support of The Centre for the Development and Evaluation of Complex Interventions for Public Health Improvement (DECIPHer), a UKCRC Public Health Research Centre of Excellence. Joint funding (MR/KO232331/1) from the British Heart Foundation, Cancer Research UK, Economic and Social Research Council, Medical Research Council, the Welsh Government and the Wellcome Trust, under the auspices of the UK Clinical Research Collaboration, is gratefully acknowledged. The work was undertaken with support from the School Health Research Network (SHRN). SHRN is part of the National Centre for Population Health and Wellbeing Research funded by Health and Care Research Wales, Welsh Government (http://www.healthandcareresearch.gov. wales/).

\section{ETHICAL APPROVAL AND INFORMED CONSENT}

Research was approved by Cardiff University School of Social Sciences Research Ethics Committee (No. SREC/2188). All participants completed an informed consent form.

\section{AUTHORS' CONTRIBUTIONS}

All authors contributed to manuscript development. RB led the qualitative elements of the main study, including design of topic guides, conducting stakeholder interviews and leading thematic analysis of transcripts. JVG, $\mathrm{JM}, \mathrm{BH}, \mathrm{OM}, \mathrm{AB}$ and $\mathrm{LB}$ contributed by conducting stakeholder interviews and reviewing data analysis after coding. JM acted as second coder on a sub-sample of transcripts. NP contributed to data analysis and manuscript content. GM oversaw the main study design and ethical approval process, as well as contributing to data analysis by reviewing final coding.

PROVENANCE AND PEER REVIEW

Not commissioned; externally peer reviewed. 